\title{
1 Excess weight mediates changes in HDL pool that reduce cholesterol efflux capacity
} and increase antioxidant activity

3 Jose Carlos de Lima-Junior ${ }^{1}$, Vitor W.M. Virginio ${ }^{1}$, Filipe A. Moura ${ }^{1,2}$, Adriana Bertolami ${ }^{3}$, Marcelo Bertolami ${ }^{3}$, Otavio R Coelho-Filho ${ }^{4}$, Ilaria Zanotti ${ }^{6}$, Wilson Nadruz ${ }^{4}$, Eliana Cotta

5 de Faria ${ }^{5}$, Luiz Sergio F. de Carvalho ${ }^{1,4}$, Andrei C Sposito ${ }^{1,4}$

6 1. Laboratory of Atherosclerosis and Vascular Biology, Faculty of Medical Sciences, State University of Campinas, São Paulo, Brazil

2. Department of Cardiology, Brigham and Women's Hospital, Boston, New England, United States

3. Department of Dyslipidemia, Dante Pazzanese Cardiological Institute, São Paulo, Brazil

4. Department of Internal Medicine, Cardiology Division, Faculty of Medical Sciences, State University of Campinas, São Paulo, Brazil

5. Lipids Laboratory, Department of Clinical Pathology, Faculty of Medical Sciences, State University of Campinas, Sao Paulo, Brazil

6. Department of Food and Drug, University of Parma, Parma, Italy

\section{Corresponding author:}

Andrei C Sposito

The authors declare no conflict of interest. 
Abbreviations: ALT, alanine aminotransferase; ApoA-I, apolipoprotein A-I; AST,

29 aspartate aminotransferase; CE, cholesteryl ester; CEC, Cholesterol efflux capacity; CETP,

30 cholesteryl ester transfer protein; cIMT, carotid intima-media thickness; FC, free cholesterol;

31 HL, hepatic lipase; HOMA2 \% $\beta$, Homeostasis model assessment 2 of beta-cell function;

32 HOMA2-IR, Homeostasis model assessment 2 of insulin resistance; HOMA2 \%S, Homeostasis

33 model assessment 2 of insulin sensitivity; HUVEC, human umbilical vein endothelial cells;

34 LCAT, Lecithin-cholesterol acyltransferase activity; PL, phospholipidis; LPL, Lipoprotein

35 lipase; PON, paraoxonase; TC, total cholesterol; PLTP, phospholipids transfer protein; VCAM-

36 1, vascular cell adhesion molecule-1. 
Abstract:

Objective: Obesity-related decline in high-density lipoprotein (HDL) functions such as

53 cholesterol efflux capacity (CEC) has supported the notion that this lipoprotein dysfunction may

54 contribute for atherogenesis among obese patients. Besides, potentially other HDL protective

55 actions may be affected with weight gain and these changes may occur even before the obesity

56 range.

Methods: Lipid profile, body mass index (BMI), biochemical measurements, and 58 carotid intima-media thickness (cIMT) were obtained in this cross-sectional study with 899

59 asymptomatic individuals. HDL functions were measured in a subgroup $(\mathrm{n}=101)$.

60 Results: Individuals with increased HDL-C had an attenuated increase in cIMT with

61 elevation of BMI. CEC, HDL-C, HDL size and HDL-antioxidant activity were negatively

62 associated with cIMT. BMI was inversely associated with HDL-mediated inhibition of platelet

63 aggregation and CEC, but surprisingly it was directly associated with the antioxidant activity.

64 Thus, even in non-obese, non-diabetic individuals, increased BMI is associated with a wide

65 change in protective functions of HDL, reducing CEC and increasing antioxidant activity. In

66 these subjects, decreased HDL concentration, size or function are related to increased

67 atherosclerotic burden.

68 Conclusion: Our findings demonstrate that in non-obese, non-diabetic individuals, the

69 increasing values of BMI are associated with impaired protective functions of HDL and

70 concomitant increase in atherosclerotic burden. 


\section{Introduction}

Presently, one in three individuals with excess weight will die from cardiovascular

80 disease (CVD)[1, 2]. In fact, both obesity (BMI $>30 \mathrm{~kg} / \mathrm{m}^{2}$ ) and overweight (BMI of 25 to $<30$

$81 \mathrm{~kg} / \mathrm{m}^{2}$ ) individuals are at increased risk of cardiovascular death as compared with those with

82 BMI within the normal range $\left(18.5\right.$ to $\left.<25 \mathrm{~kg} / \mathrm{m}^{2}\right)$ [3]. The proposed milieu for this interaction

83 involves a spectrum of mechanisms in which phenotypic or functional changes in high-density

84 lipoprotein (HDL) are involved [4].

The identification of HDL involvement in adiposopathy is not a recent issue. Since the metabolic syndrome was conceived, all clinical criteria for its diagnosis included low levels of plasma HDL-cholesterol (HDL-C) as a marker of metabolically, unhealthy obesity. In the mechanistic point of view, the combination of increased substrate, such as triglyceride-rich

89 lipoproteins, and increased activity of HDL remodeling proteins, such as cholesteryl ester

90 transfer protein (CETP), and hepatic lipase (HL), coexists in overweight individuals as a result

91 of insulin resistance, promoting a reduction in HDL concentration, size and its content of

92 apolipoproteins AI (ApoA-I). In addition, a decrease in the overall cholesterol efflux capacity

93 (CEC) has been reported in obese subjects [5], despite the increased ABCA1-mediated

94 cholesterol efflux[6].

Besides CEC, HDL also mediates several other anti-atherosclerotic mechanisms, such as antioxidant, anti-inflammatory activities and inhibition of platelet aggregation, whose extent

97 is sensitive to phenotypic changes of the particles, such as those described above. If this is so,

98 more than the reduced capacity as free cholesterol acceptor, an overall dysfunction in the HDL

99 system may follow weight gain [7]. Furthermore, as the magnitude of these phenotypic changes

100 in HDL occurs in parallel with the increase in BMI, it is possible that a cluster of particle

101 dysfunctions occurs earlier with the weight gain, possibly even before the criterion for

102 overweight. Hence, a metabolic legacy related to HDL may contribute to the future CVD risk.

103 In order to shed some light on these gaps, we designed this study to evaluate the impact of BMI 
104 on the interaction between HDL concentration and functions with atherosclerotic burden in pre-

105 obese individuals.

106 2. Materials and methods

107 2.1. Cross-sectional study description

108 We evaluated a sample of 899 asymptomatic individuals who were seen in two primary

109 care centers between 2008 and 2013: the outpatient clinic at Dante Pazzanese Institute of

110 Cardiology, São Paulo (SP), Brazil, and governmental primary care centers of the city of

111 Campinas, SP, Brazil. Inclusion criteria were: (1) no manifested atherosclerotic CVD; (2) no

112 diagnosis of type 2 diabetes based on antidiabetic treatment, fast blood glycemia $\geq 126 \mathrm{mg} / \mathrm{dL}$,

113 glycated hemoglobin $\geq 6.5 \%$ or glycemia $\geq 200 \mathrm{mg} / \mathrm{dL}$ on 120 -minutes oral tolerance test and (3)

114 age between 20 and 75 years old. We excluded individuals with (1) uncontrolled hyper (thyroid

115 stimulating hormone (TSH) $<0.41 \mu \mathrm{UI} / \mathrm{mL}$ or free thyroxin $>1.8 \mathrm{ng} / \mathrm{dL}$ ) or hypothyroidism

$116(\mathrm{TSH}>4.50 \mu \mathrm{UI} / \mathrm{mL}$ or free thyroxin $<0.9 \mathrm{ng} / \mathrm{dL})$; (2) antidiabetic medications; (3) liver disease,

117 as indicated by ALT or AST over two times the upper limit; (4) urea >40mg/dL; (5) glomerular

118 filtration rate $\leq 60 \mathrm{~mL} / \mathrm{min} / 1.73 \mathrm{~m}^{2}$; (6) heart failure NYHA stage $\geq$ III; (7) HIV positive or (8)

119 withdrawal of informed consent. Patients underwent clinical examination, as well as

120 biochemical analysis. Subclinical atherosclerosis was measured in all patients up to a month

121 after being included. The study was approved by the local institutional ethical committee of the

122 Instituto Dante Pazzanese de Cardiologia (registration number 3852/2009). It is also registered

123 at ClinicalTrials.Gov by the identification NCT02487615. All patients provided written and

124 informed consent forms before taking part in the study. The study protocol conforms to the

125 ethical guidelines of the 1975 Declaration of Helsinki.

126 A sub-analysis testing functions and characteristics of HDL was performed in

127 consecutive sample of 101 individuals from the enrolled participants in the governmental

128 primary care centers of the city of Campinas. The study was approved by the local institutional

129 ethical committee of the Hospital das Clínicas of the State University of Campinas (registration

130 number 1260/2010). It is registered at ClinicalTrials.Gov by the identification NCT02106013. 
131 All patients provided written and informed consent forms before taking part in the study. The

132 study protocol conforms to the ethical guidelines of the 1975 Declaration of Helsinki.

\section{2.2. Biochemical analysis}

134 Blood samples were drawn after a 12-hour fasting period. The following biochemical 135 measurements were performed: triglycerides, total cholesterol, HDL-C, creatinine, c-reactive 136 protein (CRP), insulin, glucose, and insulin. LDL-C was calculated using Friedewald's 137 equation. Glomerular filtration rate was calculated by the CKD-EPI equation. HOMA2 \% S,

138 HOMA2-IR and HOMA2\% $\beta$ were calculated using computer models [8].

\section{2.3. Carotid artery ultrasound}

$140 \quad$ Carotid Doppler ultrasound was performed using high-resolution Vivid 7 ultrasound 141 (GE, USA) and high-frequency linear transducer $(9 \mathrm{MHz})$ with automatic border recognizer 142 detection as described previously in Bertolami et al [9]. Briefly, the cIMT was obtained by 143 means of image processing of B-mode ultrasonograms of the right and left automatic 144 measurement. High-resolution B-mode ultra-sonographic imaging was performed initially 145 evaluating the common carotid artery with antero-oblique insonation above the clavicle and 146 alongside the internal carotid artery, as standardized procedure[10]. Measurement of cIMT was 147 obtained $20 \mathrm{~mm}$ proximally from the carotid bifurcation as the distance between the lumen148 intima interface and the media-adventitia interface[11].

\section{2.4. Lipoprotein isolation}

150 LDL was isolated from a pool of normolipidemic sera from 20 volunteers, through 151 sequential ultracentrifugation using a Beckman L8-M ultracentrifuge (Beckman Coulter Inc., 152 Palo Alto, USA), with a 75Ti fixed angle rotor (Havel, 1955 \#11). HDL was isolated from each 153 study participant through density gradient ultracentrifugation[12] with the use of a SW41Ti 154 rotor. Isolated lipoproteins were extensively dialyzed against EDTA-free PBS for $24 \mathrm{~h}$, at $4^{\circ} \mathrm{C}$, in 155 a dark room. All assays were performed in freshly isolated lipoproteins that were kept at $4^{\circ} \mathrm{C}$ for 156 a maximum period of 15 days.

\section{2.5. HDL chemical composition and molar concentration measurements}


HDL chemical composition was measured using commercially available enzymatic kits,

159 in the microplate reader Power Wave XS (BioTek®, Winooski, USA). Total proteins (Pierce ${ }^{\mathrm{TM}}$

160 BCA Protein Assay Kit, Thermo Scientific, Rockford, USA), TC (CHOD-PAP, total

161 cholesterol, Roche Diagnostics® reagents, Mannheim, Germany), FC (Free Cholesterol E,

162 Wako Chemicals, Richmond, USA), PL (Phospholipids C, Wako Chemicals, Richmond, USA),

163 TG (TG, GPO-PAP, Roche Diagnostics® reagents, Mannheim, Germany) and ApoA-I (TINA

164 QUANT APOA1 V2, Roche Diagnostics® reagents, Mannheim, Germany) were measured,

165 while CE was calculated according to the following formula: (TC-FC) x 1.67[12]. The relative

166 content of ApoA-I (HDL-ApoA-I) or lipids in HDL was calculated based on their proportion to

167 the total mass of HDL, calculated as the sum of FC, PL, TG, CE, and total proteins. HDL molar

168 concentration was estimated based on particle total mass and molecular weight[12].

\section{2.6. HDL physical-chemical characterization}

170 HDL particle size was determined using dynamic light scattering, in a Nanotrac Particle

171 Size Analyser 250 (Microtrac Inc., Montgomeryville, USA)[13]. Zeta potential was determined

172 in $\mathrm{HDL}$ diluted 1:10 in $\mathrm{KCl} 10 \mathrm{mM}$, using laser Doppler micro-electrophoresis, in the Zetasizer

173 Nano ZS (Malvern Instruments, Malvern, UK).

\section{2.7. Determination of proteins involved in HDL metabolism}

175 CETP and PLTP activities were measured using exogenous radiometric assays, as

176 previously described[14, 15]. LPL and HL activities were measured in fasted post-heparin

177 plasma samples, collected $15 \mathrm{~min}$ after the intravenous administration of heparin (100U/kg body

178 weight), in an assay based on fatty acid release from a radiolabeled triolein emulsion[16]. LCAT

179 activity was determined using recombinant HDL, according to standardized method [17]. PON

180 activity was measured using paraoxon (diethyl-p-nitrophenylphosphate, Sigma, St. Louis, MO,

181 USA) as substrate [18].

$182 \quad$ 2.8. HDL antioxidant activity

183 HDL antioxidant activity was measured in a kinetic fluorimetric assay adapted from

184 Navab et al[19]. Oxidation was monitored as changes in the fluorescence intensity of $2^{\prime}, 7^{\prime}-$

185 dichlorofluoresceine (DCFH). For the antioxidant activity assays, LDL (final concentration, 
$18620 \mathrm{mgTC} / \mathrm{dL}$ ) and $\mathrm{CuSO}_{4}$ (final concentration, $0.5 \mu \mathrm{M}$ ) were added to DCFH-containing tubes

187 (final concentration, $2 \mathrm{mg} / \mathrm{mL}$ ), followed by the addition or not of HDL (final concentration,

$18815 \mathrm{mg}$ total mass/dL). The volume was adjusted to $100 \mu \mathrm{L}$ with Chelex treated-PBS and the

189 reaction mixture transferred onto a black 96-well microplate. The plate was covered with an

190 optical adhesive cover to avoid evaporation and incubated at $37^{\circ} \mathrm{C}$. Fluorescence intensity was

191 measured over $24 \mathrm{~h}$ with 15 -minute intervals in a fluorescence microplate reader (Spectra Max

192 M5; Molecular Devices, Sunnyvale, USA) at an excitation wavelength of 485nm, emission

193 wavelength of $540 \mathrm{~nm}$, and cut-off of $530 \mathrm{~nm}$. Results of antioxidant activity are presented as the

194 percentage of inhibition of LDL oxidation in the presence of each subject's HDL when

195 compared to control wells (LDL alone).

\section{2.9. HDL anti-inflammatory activity}

197 HDL's anti-inflammatory activity was measured in HUVEC in an assay adapted from

198 Besler et al[20]. Cells were cultured in RPMI 1640 medium containing 10\% fetal calf serum,

199 penicillin, and streptomycin and maintained in a $5 \% \mathrm{CO}_{2}$ incubator at $37^{\circ} \mathrm{C}$. After reaching

200 confluence, they were plated in 24 -well culture plate $\left(3 \times 10^{5}\right.$ cells/well, and incubated with

201 TNF- $\alpha(1 \mathrm{ng} / \mathrm{mL})$, with or without HDL $(50 \mu \mathrm{g}$ ApoA-I/mL) for three hours. The culture media

202 were collected and stored at $-80^{\circ} \mathrm{C}$. Due to the low VCAM-1 concentrations, samples were

203 concentrated using the Amicon® Ultra Centrifugal Filters, 50K (Millipore, Massachusetts,

204 USA) and then VCAM-1 concentrations were measured using the Human VCAM-1 ELISA Kit

205 (Cat number ECM340, Millipore, Massachusetts, USA). Results are expressed as the percentage

206 of decrease in VCAM-1 concentrations in the wells incubated with HDL when compared to the

207 control wells without HDL.

\section{2.10. Cholesterol efflux capacity (CEC) assay}

209 Global cellular CEC was performed using J774 macrophages enriched with acetylated

210 LDL and ${ }^{14} \mathrm{C}$-cholesterol and HDL as the cholesterol acceptor[21]. In summary, J774

211 macrophages were cultured in RPMI 1640 medium containing 10\% fetal calf serum, penicillin,

212 and streptomycin and maintained in a $5 \% \mathrm{CO}_{2}$ incubator at $37^{\circ} \mathrm{C}$. After reaching confluence,

213 cells were plated in a 96-well plate $\left(1.25 \times 10^{5}\right.$ cells/well, and enriched with acetylated LDL (50 
$214 \mu \mathrm{g} / \mathrm{mL})$ and ${ }^{14} \mathrm{C}$-free cholesterol $(0.3 \mu \mathrm{Ci} / \mathrm{mL})$. After $48 \mathrm{~h}$, cells were washed with PBS

215 containing fatty acid-free albumin (FAFA) and equilibrated with DMEM containing FAFA for

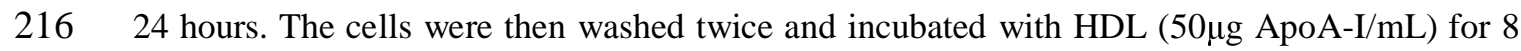

217 hours. Media were collected and the radioactivity measured in a beta-scintillation counter. Cells

218 were rinsed twice with cold physiologic saline and the intracellular lipids extracted with hexane:

219 isopropanol (3:2, v/v). Solvent was evaporated and radioactivity measured. The percentage of

$220{ }^{14} \mathrm{C}$-CEC was calculated as $\left({ }^{14} \mathrm{C}\right.$-cholesterol in the medium $/{ }^{14} \mathrm{C}$-cholesterol in cells+medium) $221 \times 100$.

\subsection{HDL-mediated platelet aggregation inhibition}

HDL ability to inhibit platelet aggregation was measured as described by Valiyaveettil et al[22]. HDL (0.8mg protein $/ \mathrm{mL})$ was mildly oxidized by dialysis against $\mathrm{PBS}+5 \mu \mathrm{M} \mathrm{CuSO}_{4}$, for $24 \mathrm{~h}$ at $37^{\circ} \mathrm{C}$. Citrated blood was drawn from a healthy donor and platelet-rich plasma (PRP) obtained by centrifugation at 800 rpm for 15 minutes. PRP was then incubated with native or oxidized HDL $(0.5 \mathrm{mg} / \mathrm{mL})$ for 30 minutes at $37^{\circ} \mathrm{C}$. Platelet aggregation was monitored using a Lumi-Aggregometer type 500 VS (Chrono-log, Havertown, USA) for 6 minutes after the addition of $\mathrm{ADP}(5 \mu \mathrm{M})$. Results are expressed as percentage of the inhibition of platelet aggregation induced by oxidized compared to native HDL.

\subsection{Statistical analysis}

The distribution of all variables was tested with Kolmogorov-Smirnov test. Jonckheere-

233 Terpstra trend in one-tail test was used to evaluate demographic, clinical variables and HDL

234 characterization among three groups clustered using BMI and expressed as median and

235 interquartile range. ANCOVA was used to perform comparisons among groups involving 236 enzymatic components of HDL adjusted for age, sex, and HOMA2 \%S. Generalized linear 237 models with type III sums of squares were used to assess interactions of BMI within the 238 association between HDL functions and cIMT, the only outcome, adjusted for age, sex, HDL-C,

239 BMI, and HOMA2 \%S. HDL functions and HDL-C were modeled with generalized linear 240 regression. The BMI effect on the cIMT among six HDL functions (HDL-C, HDL size, 241 antioxidant activity, CEC, HDL-mediated platelet inhibition, and anti-inflammatory activity) 
242 was evaluated with the use of interaction tests. We used complete case analysis to handle

243 missing data. To construct the 3D surface plot 1 , we included only HDL-C values between

244 40mg / dL and 100mg / dL; HDL size between $7.0 \mathrm{~nm}$ and $9.5 \mathrm{~nm}$; CEC between $8 \%$ and 20\%;

245 antioxidant activity between 0 and $100 \%$. For the remainder of the regression analyzes, we used

246 the entire sample size of the sub-sample of 99 individuals. Two-sided $p \leq 0.05$ were considered to

247 indicate statistical significance. Analyses were performed using IBM SPSS ${ }^{\circledR}$ version 21.0

248 statistical software. Scatter plot was performed using GraphPad Prism version 7.0 for Mac,

249 GraphPad Software, La Jolla California USA, www.graphpad.com”. Polinomial splines were

250 used to evaluate the relation between BMI or carotid IMT vs CEC or Antioxidant activity or a

251 compound variable, after transforming CEC and Antioxidant activity into positive z-scores. The

252 compound variable (Z-Efflux + Z-Antioxidant activity) was defined by the sum of z-scores for

253 CEC and antioxidant activity. In order to avoid overfitting, we excluded extreme values at x-

254 axis $(<5$ th percentile and $>95 \%$ percentile) and smoothing parameters for polinomial derivation

255 (degrees of freedom [df] and lambda) were defined after cross validation. Spline curves were

256 performed in R software, version 3.2.1 (R Foundation for Statistical Computing). We used

257 MATLAB $^{\circledR}$ (version 4.10, The MathWorks, Inc, Apple Hill Drive Natick, MA) to fit a 3D

258 curve using second polynomial least square surface.

\section{Results}

\subsection{Overall study participants characteristics}

262 The baseline characteristics of participants are shown in Table 1 stratified by BMI status 263 ( $\mathrm{n}=899)$. The female gender prevailed among the participants and BMI values were associated 264 with waist circumference, increased cIMT and impaired metabolic parameters; i.e. lower HDL265 C, Apo-AI and HOMA2\%S, as well as higher triglycerides, insulin and fasting glucose. 266 Similarly, a stepped increase in LDL-C and total cholesterol was also noted with increasing 267 BMI. 
In the whole studied sample ( $\mathrm{n}=899)$, multivariable linear regression analyses adjusted for

270 BMI, age, gender, and plasma insulin or HOMA2-IR, confirmed the association between cIMT and HDL-C $(\beta=-0.11 ; 95 \% \mathrm{CI}=-0.020 ; 0.000 ; \mathrm{p}=0.03)$ and identified the existence of a significant interaction of BMI upon this association $(\beta=-1.80 ; \mathrm{p}<0.0001)$. To visualize the

273 pattern for such BMI interaction, 3D surface plots were applied based on second polynomial

274 least square regression (Figure 1). As shown in the Figure 1A, in subjects with increased BMI,

275 reduced HDL-C levels were associated with increased cIMT. In contrast, in those individuals

276 with reduced BMI, no clear association was found between HDL-C and cIMT. In order to

277 provide a deeper assessment of this interaction, a broad spectrum of HDL functions was

278 investigated in a subgroup of these individuals. As it would be expected, an inverse association

279 was found between BMI and HDL-C (Spearman's rho $-0.028, \mathrm{p}<0.0001$ ) and HDL size

280 (Spearman's rho $-0.175, \mathrm{p}<0.0001)$.

\subsection{Association between BMI, HDL functions and cIMT in the subgroup analyses}

The subgroup characteristics are shown on Table 2. In the subgroup, we found a stepped decrease of total HDL mass, HDL size, and HDL content in triglyceride, free cholesterol, cholesteryl ester, and phospholipid across BMI categories (Table 3). PON activity adjusted for the total number of HDL particles, i.e. PON/HDL-C ratio, increased in parallel with BMI categories. There was no relation between BMI categories and activities of PLTP, LCAT, HL or LPL (Table 3).

In line with previous studies, as shown in Figure $2 \mathrm{~A}$ (linear beta -0.38 , polynomial $\mathrm{R} 2=0.19, \mathrm{p}=0.001$; Spearman's rho $-0.32, \mathrm{p}<0.001)$, we reported a progressive decline in CEC

290 as BMI increases. In contrast, we found a progressive increase in HDL antioxidant activity 291 which was proportional and reciprocal as compared with CEC (linear beta +1.38 , polynomial $292 \mathrm{R} 2=0.12, \mathrm{p}=0.04$ ) (Figure $2 \mathrm{~B}$ ). Both changes were mainly mediated by the HDL size which is 293 inversely related to weight gain. Based on this assumption, the compound variable of $\mathrm{z}$ 294 transformed efflux plus antioxidant activity should remain approximately constant as HDL size 295 changes due to excess weight ( $\mathrm{p}$ value 0.75) (Figure 2C). Increasing values of the compound 
variable were associated lower carotid IMT (linear beta -0.10 , polynomial R2 $=0.26, \mathrm{p}<0.001$ )

297 (Figure 2D). Still, correlation analyses were made between BMI and HDL functions. An inverse association was also found with HDL-mediated platelet inhibition (Spearman's rho $-0.157, \mathrm{p}<$ 0.03). No correlation was found between BMI and HDL anti-inflammatory activity (Spearman’s

300 rho $-0.009, \mathrm{p}<0.904)$ nor between each of the HDL functions.

301 Since both the abundance of substrate, i.e. triglyceride-rich lipoproteins, and the activities of 302 transport proteins are potentially involved in the effect of excess weight on HDL phenotype, 303 multivariate linear regression models were applied to estimate the influence of intravascular 304 HDL-remodeling proteins, i.e. CETP, LPL, HL, LCAT and PLTP on HDL size. CETP $(\beta=-0.12$; $30595 \% \mathrm{CI}=-0.30 ;-0.01 ; \mathrm{p}=0.030), \mathrm{HL}(\beta=-0.28 ; 95 \% \mathrm{CI}=-0.35 ;-0.12 ; \mathrm{p}<0.0001)$ and LCAT $(\beta=-$ $306 \quad 0.36 ; 95 \% \mathrm{CI}=-0.28 ;-0.13 ; \mathrm{p}<0.0001)$ were drivers for HDL size. HDL size was also associated 307 with plasma triglycerides $(\beta=-0.17 ; 95 \% \mathrm{CI}=-0.06 ;-0.02 ; \mathrm{p}<0.001)$, HOMA2-IR $(\beta=0.21$; $95 \% \mathrm{CI}=0.01 ; 0.42 ; \mathrm{p}=0.001), \mathrm{PON}$ activity/HDL-C $(\beta=-0.33 ; 95 \% \mathrm{CI}=-0.47 ;-0.13 ; \mathrm{p}<0.0001)$ and HDL-mediated antioxidant activity $(\beta=-0.70 ; 95 \% \mathrm{CI}=-0.81 ;-0.12 ; \mathrm{p}=0.009)$. Association

310 was found between HOMA2-IR and HDL-mediated antioxidant activity $(\beta=-2.1 ; 95 \% \mathrm{CI}=-$ $3113.66 ;-0.60 ; \mathrm{p}=0.007)$.

312 In order to estimate the association between HDL functions and cIMT, we used multiple 313 linear regression with adjustments for the following confounders (BMI, age, sex, HDL-c and 314 insulin), which were selected based on univariate significance or clinical relevance (age, sex) 315 (Table 4). We observed a negative association between CEC and cIMT, which remained 316 significant after initial adjustment for the same confounders above, or even after adjustment for 317 HDL size $(\beta=-0.18 ; 95 \% \mathrm{CI}=-0.138 ;-0.011 ; \mathrm{p}=0.02)$, antioxidant activity $(\beta=-0.19 ; 95 \% \mathrm{CI}=-$ $3180.003 ; 0.000 ; \mathrm{p}=0.04)$ and PON activity/HDL-C $(\beta=-0.16 ; 95 \% \mathrm{CI}=-0.065 ;-0.002 ; \mathrm{p}=0.02)$. The 319 antioxidant activity of HDL was also inversely related to cIMT. Anti-inflammatory activity, 320 PON activity/HDL-C and HDL-mediated platelet inhibition were not associated with cIMT in 321 an adjusted model.

322 Interactions of BMI were found within the linear associations between cIMT and CEC $323(\mathrm{p}=0.03)$, and cIMT and antioxidant activity $(\mathrm{p}=0.04)$. Although the 95\% CI suggests a tendency 
324 towards a moderating effect of the BMI on the association between HDL size and cIMT, this

325 interaction did not reach statistical significance ( $\mathrm{p}=0.13$ ) (Fig. 1B). As displayed in Fig 1C, the

326 inverse association between CEC and cIMT seems to increase in parallel with BMI values. In

327 contrast, as shown in Fig 1D, the inverse association between cIMT and antioxidant activity of

328 HDL increases with increasing BMI. In fact, the correlation between cIMT and antioxidant

329 activity is greater in individuals with BMI above the median $(23.6 \mathrm{~kg} / \mathrm{m} 2)(\mathrm{r}=-0.33 ; \mathrm{p}=0.037)$

330 than in their counterparts $(\mathrm{r}=-0.2 ; \mathrm{p}=0.05)$ while the correlation between CEC and cIMT is equal

331 in both subgroups (above, $\mathrm{r}=-0.28 ; \mathrm{p}=0.042$; below, $\mathrm{r}=-0.28 ; \mathrm{p}=0.016$ ).

\section{Discussion}

Recent data have shown that the predictive value of HDL-C for estimating the risk of cardiovascular events declines after CVD manifestation[23]; a failure that has been attributed to the increased generation of dysfunctional HDL in a setting of chronic or acute disease. As pointed out in subjects with CVD, we hypothesized that excess weight may influence the

340 hypothesis, we moved forward investigating whether more subtle changes in the HDL system 341 could occur in overweight individuals and whether this could justify a change in the association 342 pattern between HDL-C and atherosclerotic disease. Taken together, our findings revealed the

343 following evidence: (i) the pattern of association between HDL-C and cIMT differs according to

344 the presence or absence of excess weight; (ii) increased BMI is associated with the simultaneous 345 change of multiple anti-atherosclerotic functions of HDL, including CEC and antioxidant 346 activity; (iii) the existing association between excess weight and carotid atherosclerotic burden

347 is in part attributable to HDL dysfunction; and (iv) HDL-mediated inhibition of platelet 348 aggregation declines with excess weight.

349 To the best of our knowledge, only few studies have previously assessed the impact of 350 body weight on HDL function in non-obese individuals and none used a simultaneous 351 assessment of multiple functions. In this clinical setting, CEC has been the main HDL function 

this specific aspect, our results are in line with previous studies. resistance is the cornerstone for CVD risk. As a result of insulin resistance, for example, there is an increase in the fatty acid efflux and in the activities of CETP and HL leading to a reduction in HDL size, an increase in the ApoA-I catabolic rate and a reduction in CEC[5, 25, 26]. In contrast with the evidence in obese subjects [27-29], our study did not identify changes in CETP and $\mathrm{HL}$ activities across BMI categories although their activities were associated with HDL size change. Thus, at this stage of excess weight, the biochemical and size changes in HDL particles is more likely a consequence of increased substrate for HDL particle remodeling, i.e. increased plasma concentration of triglyceride-rich lipoproteins.

These changes in the HDL system have traditionally been reported as a component cause for the increased risk of CVD in obese individuals[30]. In those who are overweight but

367 below the obesity threshold, we revealed a similar scenario, i.e. insulin resistance inversely 368 relates with overweight, HDL size and CEC. It is interesting to note that these changes occurred 369 even before the threshold for overweight as defined by World Health Organization (WHO).

370 Thus, according to previous translational studies[31] or actuarial analyzes based on observational cohorts[32], our data support the concept that the threshold for pathogenic body mass is probably below the WHO definition.

Although it is clear that there is functional impairment, it is plausible that the change in

374 the HDL phenotype would have an adaptive biological purpose motivated by the chronic 375 increase of oxidative stress and by low-grade systemic inflammation. Similar reduction of HDL 376 size has been reported in individuals who exhibit acute phase response, such as in myocardial 377 infarction[33] and sepsis[34]. In these conditions, the reduction of HDL size is associated with a 378 greater capacity to mitigate the oxidative stress. In agreement with this and consistent with 379 previous studies, HDL size was inversely associated with increased antioxidant and PON 

that estimates of the magnitude of HDL participation in the CVD risk in excess weight are naturally imprecise unless a broad range of anti-atherosclerotic functions is simultaneously investigated.

Obesity is clearly shown to be a prothrombotic state resulting from a combination of increased thrombin generation, platelet hyperactivity and decreased fibrinolysis[36]. Increased platelet reactivity is the result of the interaction between multiple characteristics grouped into obesity, including inflammation, oxidative stress, insulin resistance and adiposopathy with change in adipokine secretion pattern. Our study added to this state of knowledge, a new mechanism of imbalance in platelet activity; inhibition of HDL-mediated platelet aggregation was inversely associated with BMI. This finding should be considered in the set of prothrombotic changes of excess weight and as one of the mechanisms by which there is an increase in the incidence of cardiovascular events in these individuals. sectional design. In addition, due to the intensive laborious methodology involved in studying a full breadth of HDL function and metabolic pathways, we may have not been able to maintain

400 the desired statistical power obtained as when the entire studied population was analyzed. In

401 spite of this, it does provide us a unique opportunity to evaluate the association between excess 402 weight and the HDL system early in the spectrum of metabolic derangement and atherogenesis.

403 In fact, this may especially be true given the low rates of insulin resistance and more favorable 404 lipid profile and systemic inflammatory activity of our study's participants.

405 In conclusion, our study indicates that higher BMI, even in non-obese, non-diabetic 406 individuals, is associated with decreased function of several protective activities of HDL. In 407 individuals with increased BMI, HDL dysfunction is directly associated with increased 
medRxiv preprint doi: https://doi.org/10.1101/19002899; this version posted July 25, 2019. The copyright holder for this preprint (which was not

certified by peer review) is the author/funder, who has granted medRxiv a license to display the preprint in perpetuity. It is made available under a CC-BY-NC-ND 4.0 International license.

408 atherosclerotic burden. Antioxidant activity is found to be an exception increasing with BMI 409 and it partially attenuated the atherosclerotic burden. 
410 Declaration of interest: The authors declare no conflict of interest.

411 Funding The study was supported by São Paulo Research Foundation (FAPESP 2010/00201-8

412 and FAPESP 2006/60585-9 and CNPq (471380/2008-13). JCLJ was supported by a doctoral

413 grant from Coordination for the Improvement of Higher-Level Education Personnel (Capes

414 grant number PROEX0092045). NBP was supported by a doctoral grant (number 2012/01645-

415 2) from the Foundation for Research Support of the State of Sao Paulo (FAPESP). Prof Sposito

416 was supported by a fellowship grant of productivity in research from the National Council for

417 Scientific and Technological Development (CNPq) (grant number 301465/2017-7).

418 Author contribution statement: Jose Carlos de Lima-Junior drafted the manuscript and

419 participated on the analysis of the data, Vitor W.M. Virginio participated on the experiments,

420 Filipe A. Moura participated on the drafting of the manuscript and analysis of the data, Adriana

421 Bertolami participated on the experiments, Marcelo Bertolami participated critically reviewing

422 the manuscript, Wilson Nadruz participated critically reviewing the manuscript, Eliana Cota de

423 Faria participated on the experiments and analysis of the data, Ilaria Zanotti participated

424 critically reviewing the manuscript, Luiz Sergio F. de Carvalho participated on the analysis of

425 the data and critically reviewing the manuscript, Andrei C Sposito participated on the analysis

426 of the data and critically reviewing the manuscript

427 Acknowledgements. We thank Natalia B. Panzoldo from the University of Campinas for 428 technical assistance in HDL functions experiments. 
[1] D.K. Tobias, A. Pan, C.L. Jackson, E.J. O'Reilly, E.L. Ding, W.C. Willett, J.E. Manson, F.B. Hu,

433 Body-mass index and mortality among adults with incident type 2 diabetes, $N$ Engl J Med

434 370(3) (2014) 233-44.

435 [2] A. Afshin, M.H. Forouzanfar, M.B. Reitsma, P. Sur, K. Estep, A. Lee, L. Marczak, A.H.

436 Mokdad, M. Moradi-Lakeh, M. Naghavi, J.S. Salama, T. Vos, K.H. Abate, C. Abbafati, M.B.

437 Ahmed, Z. Al-Aly, A. Alkerwi, R. Al-Raddadi, A.T. Amare, A. Amberbir, A.K. Amegah, E. Amini, 438 S.M. Amrock, R.M. Anjana, J. Ärnlöv, H. Asayesh, A. Banerjee, A. Barac, E. Baye, D.A. Bennett, 439 A.S. Beyene, S. Biadgilign, S. Biryukov, E. Bjertness, D.J. Boneya, I. Campos-Nonato, J.J. Carrero, 440 P. Cecilio, K. Cercy, L.G. Ciobanu, L. Cornaby, S.A. Damtew, L. Dandona, R. Dandona, S.D.

441 Dharmaratne, B.B. Duncan, B. Eshrati, A. Esteghamati, V.L. Feigin, J.C. Fernandes, T. Fürst, T.T. 442 Gebrehiwot, A. Gold, P.N. Gona, A. Goto, T.D. Habtewold, K.T. Hadush, N. Hafezi-Nejad, S.I.

443 Hay, M. Horino, F. Islami, R. Kamal, A. Kasaeian, S.V. Katikireddi, A.P. Kengne, C.N.

444 Kesavachandran, Y.S. Khader, Y.H. Khang, J. Khubchandani, D. Kim, Y.J. Kim, Y. Kinfu, S. Kosen, 445 T. Ku, B.K. Defo, G.A. Kumar, H.J. Larson, M. Leinsalu, X. Liang, S.S. Lim, P. Liu, A.D. Lopez, R. 446 Lozano, A. Majeed, R. Malekzadeh, D.C. Malta, M. Mazidi, C. McAlinden, S.T. McGarvey, D.T. 447 Mengistu, G.A. Mensah, G.B.M. Mensink, H.B. Mezgebe, E.M. Mirrakhimov, U.O. Mueller, J.J. 448 Noubiap, C.M. Obermeyer, F.A. Ogbo, M.O. Owolabi, G.C. Patton, F. Pourmalek, M. Qorbani, A. 449 Rafay, R.K. Rai, C.L. Ranabhat, N. Reinig, S. Safiri, J.A. Salomon, J.R. Sanabria, I.S. Santos, B. 450 Sartorius, M. Sawhney, J. Schmidhuber, A.E. Schutte, M.I. Schmidt, S.G. Sepanlou, M. Shamsizadeh, S. Sheikhbahaei, M.J. Shin, R. Shiri, I. Shiue, H.S. Roba, D.A.S. Silva, J.I. Silverberg, J.A. Singh, S. Stranges, S. Swaminathan, R. Tabarés-Seisdedos, F. Tadese, B.A. Tedla, B.S. Tegegne, A.S. Terkawi, J.S. Thakur, M. Tonelli, R. Topor-Madry, S. Tyrovolas, K.N. Ukwaja, O.A. Uthman, M. Vaezghasemi, T. Vasankari, V.V. Vlassov, S.E. Vollset, E. Weiderpass, A.

Werdecker, J. Wesana, R. Westerman, Y. Yano, N. Yonemoto, G. Yonga, Z. Zaidi, Z.M. Zenebe, B. Zipkin, C.J.L. Murray, G.O. Collaborators, Health Effects of Overweight and Obesity in 195 Countries over 25 Years, N Engl J Med 377(1) (2017) 13-27.

[3] A.A. Khan, P.A. Mundra, N.E. Straznicky, P.J. Nestel, G. Wong, R. Tan, K. Huynh, T.W. Ng, N.A. Mellett, J.M. Weir, C.K. Barlow, Z.H. Alshehry, G.W. Lambert, B.A. Kingwell, P.J. Meikle, Weight Loss and Exercise Alter the High-Density Lipoprotein Lipidome and Improve HighDensity Lipoprotein Functionality in Metabolic Syndrome, Arterioscler Thromb Vasc Biol 38(2) (2018) 438-447.

463 [4] F.M. Sacks, M.K. Jensen, From High-Density Lipoprotein Cholesterol to Measurements of 464 Function: Prospects for the Development of Tests for High-Density Lipoprotein Functionality in Cardiovascular Disease, Arterioscler Thromb Vasc Biol 38(3) (2018) 487-499.

[5] T. Sasahara, P. Nestel, N. Fidge, D. Sviridov, Cholesterol transport between cells and high density lipoprotein subfractions from obese and lean subjects, J Lipid Res 39(3) (1998) 544-54. [6] N. Attia, N. Fournier, B. Vedie, M. Cambillau, P. Beaune, O. Ziegler, A. Grynberg, J.L. Paul, B. Guerci, Impact of android overweight or obesity and insulin resistance on basal and postprandial SR-BI and ABCA1-mediated serum cholesterol efflux capacities, Atherosclerosis 209(2) (2010) 422-9.

472 [7] A.C. Sposito, HDL metrics, let's call the number thing off?, Atherosclerosis 251 (2016) 525473527.

474 [8] J.C. Levy, D.R. Matthews, M.P. Hermans, Correct homeostasis model assessment (HOMA) 475 evaluation uses the computer program, Diabetes Care 21(12) (1998) 2191-2.

476 [9] A. Bertolami, J.C. de Lima-Júnior, R.M. Cintra, L.S. Carvalho, C.C. Gonzaga, M.L. Sulzbach, 477 A.C.G.P. Petisco, J.E.M. Barbosa, A.A. Faludi, J. Plutzky, M.C. Bertolami, A.C. Sposito,

478 Adiponectin concentration data improve the estimation of atherosclerotic risk in normal and in 479 overweight subjects, Clin Endocrinol (Oxf) (2017). 
[10] J.H. Stein, C.E. Korcarz, R.T. Hurst, E. Lonn, C.B. Kendall, E.R. Mohler, S.S. Najjar, C.M. cardiovascular disease risk: a consensus statement from the American Society of

484 Echocardiography Carotid Intima-Media Thickness Task Force. Endorsed by the Society for

485 Vascular Medicine, Journal of the American Society of Echocardiography : official publication

486 of the American Society of Echocardiography 21(2) (2008) 93-111; quiz 189-90.

487 [11] M.W. Lorenz, S. von Kegler, H. Steinmetz, H.S. Markus, M. Sitzer, Carotid intima-media

488 thickening indicates a higher vascular risk across a wide age range: prospective data from the

489 Carotid Atherosclerosis Progression Study (CAPS), Stroke 37(1) (2006) 87-92.

490 [12] M.J. Chapman, S. Goldstein, D. Lagrange, P.M. Laplaud, A density gradient ultracentrifugal

491 procedure for the isolation of the major lipoprotein classes from human serum, J Lipid Res

492 22(2) (1981) 339-58.

493 [13] E.S. Lima, R.C. Maranhao, Rapid, simple laser-light-scattering method for HDL particle

494 sizing in whole plasma, Clin Chem 50(6) (2004) 1086-8.

495 [14] L. Lagrost, Determination of the mass concentration and the activity of the plasma

496 cholesteryl ester transfer protein (CETP), Methods Mol Biol 110 (1998) 231-41. [15] M. Jauhiainen, C. Ehnholm, Determination of human plasma phospholipid transfer protein mass and activity, Methods 36(2) (2005) 97-101.

[16] C. Ehnholm, T. Kuusi, Preparation, characterization, and measurement of hepatic lipase, Methods Enzymol 129 (1986) 716-38.

[17] J.W. Chisholm, A.K. Gebre, J.S. Parks, Characterization of C-terminal histidine-tagged human recombinant lecithin:cholesterol acyltransferase, J Lipid Res 40(8) (1999) 1512-9. [18] D.Z. Scherrer, V.H. Zago, I.C. Vieira, E.S. Parra, N.B. Panzoldo, F. Alexandre, R. Secolin, J. Baracat, E.C. Quintão, E.C. Faria, p.Q192R SNP of PON1 seems not to be Associated with Carotid Atherosclerosis Risk Factors in an Asymptomatic and Normolipidemic Brazilian Population Sample, Arq Bras Cardiol 105(1) (2015) 45-52.

[19] M. Navab, S.Y. Hama, G.P. Hough, G. Subbanagounder, S.T. Reddy, A.M. Fogelman, A cellfree assay for detecting HDL that is dysfunctional in preventing the formation of or inactivating oxidized phospholipids, J Lipid Res 42(8) (2001) 1308-17.

[20] C. Besler, K. Heinrich, L. Rohrer, C. Doerries, M. Riwanto, D.M. Shih, A. Chroni, K. Yonekawa, S. Stein, N. Schaefer, M. Mueller, A. Akhmedov, G. Daniil, C. Manes, C. Templin, C. Wyss, W. Maier, F.C. Tanner, C.M. Matter, R. Corti, C. Furlong, A.J. Lusis, A. von Eckardstein, A.M. Fogelman, T.F. Luscher, U. Landmesser, Mechanisms underlying adverse effects of HDL on eNOS-activating pathways in patients with coronary artery disease, J Clin Invest 121(7) (2011) 2693-708.

[21] A. Machado-Lima, R.T. Iborra, R.S. Pinto, C.H. Sartori, E.R. Oliveira, E.R. Nakandakare, J.T. Stefano, D. Giannella-Neto, M.L. Correa-Giannella, M. Passarelli, Advanced glycated albumin isolated from poorly controlled type 1 diabetes mellitus patients alters macrophage gene expression impairing ABCA-1-mediated reverse cholesterol transport, Diabetes Metab Res Rev 29(1) (2013) 66-76.

[22] M. Valiyaveettil, N. Kar, M.Z. Ashraf, T.V. Byzova, M. Febbraio, E.A. Podrez, Oxidized highdensity lipoprotein inhibits platelet activation and aggregation via scavenger receptor $\mathrm{Bl}$, Blood 111(4) (2008) 1962-71.

[23] G. Silbernagel, B. Schottker, S. Appelbaum, H. Scharnagl, M.E. Kleber, T.B. Grammer, A. Ritsch, U. Mons, B. Holleczek, G. Goliasch, A. Niessner, B.O. Boehm, R.B. Schnabel, H. Brenner, S. Blankenberg, U. Landmesser, W. Marz, High-density lipoprotein cholesterol, coronary artery disease, and cardiovascular mortality, Eur Heart J 34(46) (2013) 3563-71.

[24] D. Saleheen, R. Scott, S. Javad, W. Zhao, A. Rodrigues, A. Picataggi, D. Lukmanova, M.L. Mucksavage, R. Luben, J. Billheimer, J.J. Kastelein, S.M. Boekholdt, K.T. Khaw, N. Wareham, D.J. Rader, Association of HDL cholesterol efflux capacity with incident coronary heart disease 531 events: a prospective case-control study, Lancet Diabetes Endocrinol 3(7) (2015) 507-13. 
532 [25] E.S. Parra, N.B. Panzoldo, V.H. Zago, D.Z. Scherrer, F. Alexandre, J. Bakkarat, V.S. Nunes, 533 E.R. Nakandakare, E.C. Quintao, W. Nadruz, Jr., E.C. de Faria, A.C. Sposito, HDL size is more 534 accurate than HDL cholesterol to predict carotid subclinical atherosclerosis in individuals 535 classified as low cardiovascular risk, PLoS One 9(12) (2014) e114212.

536 [26] M. de la Llera Moya, F.C. McGillicuddy, C.C. Hinkle, M. Byrne, M.R. Joshi, V. Nguyen, J. 537 Tabita-Martinez, M.L. Wolfe, K. Badellino, L. Pruscino, N.N. Mehta, B.F. Asztalos, M.P. Reilly, 538 Inflammation modulates human HDL composition and function in vivo, Atherosclerosis 222(2) 539 (2012) 390-4.

540 [27] T. Arai, S. Yamashita, K. Hirano, N. Sakai, K. Kotani, S. Fujioka, S. Nozaki, Y. Keno, M.

541 Yamane, E. Shinohara, Increased plasma cholesteryl ester transfer protein in obese subjects. A 542 possible mechanism for the reduction of serum HDL cholesterol levels in obesity, Arterioscler 543 Thromb 14(7) (1994) 1129-36.

544 [28] C.F. Ebenbichler, M. Laimer, S. Kaser, A. Ritsch, A. Sandhofer, H. Weiss, F. Aigner, J.R. 545 Patsch, Relationship between cholesteryl ester transfer protein and atherogenic lipoprotein 546 profile in morbidly obese women, Arterioscler Thromb Vasc Biol 22(9) (2002) 1465-9.

547 [29] C.P.J. Talbot, J. Plat, P.J. Joris, M. Konings, Y.H.A.M. Kusters, C.G. Schalkwijk, A. Ritsch, R.P. 548 Mensink, HDL cholesterol efflux capacity and cholesteryl ester transfer are associated with 549 body mass, but are not changed by diet-induced weight loss: A randomized trial in abdominally 550 obese men, Atherosclerosis 274 (2018) 23-28.

551 [30] B. Shao, C. Tang, A. Sinha, P.S. Mayer, G.D. Davenport, N. Brot, M.N. Oda, X.Q. Zhao, J.W. 552 Heinecke, Humans with atherosclerosis have impaired ABCA1 cholesterol efflux and enhanced 553 high-density lipoprotein oxidation by myeloperoxidase, Circ Res 114(11) (2014) 1733-42.

554 [31] L.H. Bogl, S. M. Kaye, J.T. Ramo, A.J. Kangas, P. Soininen, A. Hakkarainen, J. Lundbom, N.

555 Lundbom, A. Ortega-Alonso, A. Rissanen, M. Ala-Korpela, J. Kaprio, K.H. Pietilainen, Abdominal 556 obesity and circulating metabolites: A twin study approach, Metabolism 65(3) (2016) 111-21.

557 [32] K. Bhaskaran, I. Dos-Santos-Silva, D.A. Leon, I.J. Douglas, L. Smeeth, Association of BMI 558 with overall and cause-specific mortality: a population-based cohort study of 3.6 million adults 559 in the UK, Lancet Diabetes Endocrinol (2018).

560 [33] L.S. Carvalho, V.W. Virginio, N.B. Panzoldo, V.N. Figueiredo, S.N. Santos, R.G. Modolo, J.M. 561 Andrade, E.S.J.C. Quinaglia, W. Nadruz-Junior, E.C. de Faria, A.C. Sposito, G. Brasilia Heart 562 Study, Elevated CETP activity during acute phase of myocardial infarction is independently 563 associated with endothelial dysfunction and adverse clinical outcome, Atherosclerosis $237(2)$ 564 (2014) 777-83.

565 [34] A. Pirillo, A.L. Catapano, G.D. Norata, HDL in infectious diseases and sepsis, Handb Exp 566 Pharmacol 224 (2015) 483-508.

567 [35] A. Kontush, S. Chantepie, M.J. Chapman, Small, dense HDL particles exert potent

568 protection of atherogenic LDL against oxidative stress, Arterioscler Thromb Vasc Biol 23(10)

569 (2003) 1881-8.

570 [36] F. Santilli, N. Vazzana, R. Liani, M.T. Guagnano, G. Davi, Platelet activation in obesity and 571 metabolic syndrome, Obes Rev 13(1) (2012) 27-42. 
574 Figure 1. 3D surface plot showing the association between BMI, cIMT, and HDL

575 variables. This surface plot displays an image based on the relationship between the BMI and

576 HDL variables as predictors on the $\mathrm{x}$ - and $\mathrm{y}$-axes and a continuous surface that represents the

577 cIMT values on the z-axis. The peak on the plot corresponds with the yellow color and the

578 highest value obtained to cIMT using the combination of $\mathrm{X}$ and $\mathrm{Y}$ that produce the maxima

579 cIMT, which occurs at approximately $0.8 \mathrm{~mm}$. The valley corresponds with blue color and the

580 combination of $\mathrm{X}$ and $\mathrm{Y}$ that produce the minima cIMT. Figure 1A, HDL-C values. Figure 1B,

581 HDL size. Figure 1C, CEC values. Figure 1D, antioxidant activity of HDL. HDL-C, high-

582 density lipoprotein cholesterol in $\mathrm{mg} / \mathrm{dL}$. BMI, body mass index in $\mathrm{kg} / \mathrm{m}^{2}$. CEC is expressed as

583 a percentage of efflux in the sample, normalized to a reference sample. Antioxidant activity is

584 expressed in \% as inhibition of LDL oxidation in the presence of each subject's HDL oxidation.

585 Figure 2. Polynomial splines showing the associations between BMI, cIMT and HDL

586 variables. $2 \mathrm{~A}$, $\mathrm{CEC}$ according to $\mathrm{BMI}$ values. $2 \mathrm{~B}$, Antioxidant activity according to BMI

587 values. $2 \mathrm{C}$, compound variable (Z-Efflux + Z-Antioxidant activity) according to BMI values.

588 2D, cIMT values according to compound variable (Z-Efflux + Z-Antioxidant activity). Gray

589 shading indicates $95 \%$ confidence intervals.

590

591

592

593

594

595

596

597

598

599

600

601 
medRxiv preprint doi: https://doi.org/10.1101/19002899; this version posted July 25, 2019. The copyright holder for this preprint (which was not certified by peer review) is the author/funder, who has granted medRxiv a license to display the preprint in perpetuity. It is made available under a CC-BY-NC-ND 4.0 International license.

602 Table 1. Clinical characteristics according to BMI groups

\section{BMI categories $(\mathrm{kg} / \mathrm{m} 2)$}

\begin{tabular}{|c|c|c|c|c|}
\hline & $<22$ & 22-24.99 & $25-30$ & $p$-value \\
\hline Sample size & 186 & 264 & 449 & \\
\hline BMI, $\mathrm{kg} / \mathrm{m}^{2}$ & $20.6(1.8)$ & $23.6(1.6)^{\mathrm{a}}$ & $28(4.6)^{\mathrm{b}, \mathrm{c}}$ & $<0.0001$ \\
\hline Waist circumference, $\mathrm{cm}$ & $68(9)$ & $75(11)^{\mathrm{a}}$ & $94(19)^{\mathrm{b}, \mathrm{c}}$ & $<0.0001$ \\
\hline Age, yr & $38(24)$ & $45.5(26)^{\mathrm{a}}$ & $54(16)^{b}$ & 0.003 \\
\hline Male sex, \% & 43.5 & 44.7 & 39.6 & 0.369 \\
\hline Hypertension, \% & 28.6 & 31.3 & 28.3 & 0.915 \\
\hline Glucose, $\mathbf{m g} / \mathbf{d L}$ & $81(12.0)$ & $86(14.0)^{\mathrm{a}}$ & $105(62.0)^{\mathrm{b}, \mathrm{c}}$ & $<0.0001$ \\
\hline Insulin, $\mu \mathrm{U} / \mathrm{mL}$ & $3.0(2.5)$ & $4.7(4.9)^{\mathrm{a}}$ & $10.2(8.2)^{\mathrm{b}, \mathrm{c}}$ & $<0.0001$ \\
\hline HOMA2 \% $\beta$ & $61.9(38.2)$ & $61.3(49.4)$ & $64.9(51.3)^{b, c}$ & 0.008 \\
\hline HOMA2 \%S & $241.7(210.3)$ & $161.2(183.5)$ & $68.8(62.5)^{b, c}$ & $<0.0001$ \\
\hline HOMA2-IR & $0.46(0.4)$ & $0.51(0.5)$ & $0.66(0.5)^{\mathrm{b}, \mathrm{c}}$ & $<0.0001$ \\
\hline CRP, mg/dL & $0.42(0.9)$ & $0.70(1.1)$ & $0.51(1.0)$ & 0.453 \\
\hline Triglycerides, mg/dL & $66(34)$ & $81(46)^{\mathrm{a}}$ & $118(87)^{b, c}$ & $<0.0001$ \\
\hline LDL-C, mg/dL & $95(40)$ & $104(34)^{\mathrm{a}}$ & $107(42)^{b}$ & $<0.0001$ \\
\hline Total cholesterol, mg/dL & $175(53)$ & $181(50)$ & $187(55)^{\mathrm{b}, \mathrm{c}}$ & $<0.0001$ \\
\hline ApoA-I, mg/dL & $148(53)$ & $142(46)$ & $137(38)^{b, c}$ & $<0.0001$ \\
\hline ApoB, mg/dL & $72(23)$ & $81(27)^{\mathrm{a}}$ & $90(31)^{\mathrm{b}}$ & $<0.0001$ \\
\hline HDL-C, mg/dL & $63(29)$ & $52(30)^{\mathrm{a}}$ & $45(19)^{\mathrm{b}, \mathrm{c}}$ & $<0.0001$ \\
\hline
\end{tabular}


cIMT, mm

$$
0.55(0.20) \quad 0.60(0.20)^{\mathrm{a}}
$$

604 All continuous variables are expressed as medians and interquartile ranges, and categorical

605 variables as percentages. Comparisons between groups were analyzed with Jonckheere-

606 Terpstra's for ordered alternatives with pairwise comparisons, or Chi-Square test for the

607 categorical variables. To convert the values for glucose to millimoles per liter, divide by 18 .

608 To convert the values for insulin to picomoles per liter, multiply by 6.945 . To convert the

609 values for cholesterol to millimoles per liter, multiply by 0.02586 . To convert the values for

610 triglycerides to millimoles per liter, multiply by $0.01129 .{ }^{\mathrm{a}} \mathrm{BMI} 22-24.9$ vs BMI $<22$; ${ }^{\mathrm{b}} \mathrm{BMI}$

$611>25$ vs $22-24.9 ;{ }^{c} \mathrm{BMI}>25$ vs BMI $<22$. Significant $\mathrm{p}$-value $<0.05$.

612

613

614

615

616

617

618

619

620

621

622

623

624

625

626

627

628 
medRxiv preprint doi: https://doi.org/10.1101/19002899; this version posted July 25, 2019. The copyright holder for this preprint (which was not certified by peer review) is the author/funder, who has granted medRxiv a license to display the preprint in perpetuity. It is made available under a CC-BY-NC-ND 4.0 International license .

Table 2. Subgroup clinical characteristics according to BMI groups

\section{BMI categories $(\mathrm{kg} / \mathrm{m} 2)$}

\begin{tabular}{|c|c|c|c|c|c|}
\hline & $<22$ & 22-24.99 & $25-30$ & $p$-value & \\
\hline Sample size & 34 & 47 & 20 & & \\
\hline BMI, $\mathrm{kg} / \mathrm{m}^{2}$ & & $20.0(2.5)$ & $23.5(1.6)^{\mathrm{a}}$ & $26.7(2.55)^{b, c}$ & $<0.0001$ \\
\hline Waist circumference, $\mathrm{cm}$ & & $65.0(7.0)$ & $75.5(13.2)^{\mathrm{a}}$ & $84.0(10.5)^{\mathrm{b}, \mathrm{c}}$ & $<0.0001$ \\
\hline Age, yr & & $42(21)$ & 39 (20.7) & $47(9.5)$ & 0.24 \\
\hline Male sex, \% & & 33.7 & 46.5 & 19.8 & 0.47 \\
\hline Glucose, $\mathrm{mg} / \mathrm{dL}$ & & $80.0(8.0)$ & $83.0(9.2)$ & $86.0(11.5)^{\mathrm{b}}$ & 0.012 \\
\hline Insulin, $\mu \mathrm{U} / \mathrm{mL}$ & & $2.5(2.0)$ & $4.3(4.0)^{\mathrm{a}}$ & $5.8(6.0)^{\mathrm{b}, \mathrm{c}}$ & $<0.0001$ \\
\hline HOMA2 \% $\beta$ & & $58.4(37.8)$ & $69.0(45.9)$ & $84.9(38.7)^{\mathrm{b}}$ & $<0.0001$ \\
\hline HOMA2 \%S & & $303.2(261.6)$ & $228.2(221.9)^{\mathrm{a}}$ & $148.2(75.1)^{\mathrm{b}, \mathrm{c}}$ & $<0.0001$ \\
\hline HOMA2-IR & & $0.3(0.3)$ & $0.4(0.5)^{\mathrm{a}}$ & $0.7(0.5)^{\mathrm{b}, \mathrm{c}}$ & $<0.0001$ \\
\hline CRP, mg/dL & & $0.9(1.5)$ & $0.71(1.2)$ & $0.6(1.2)$ & 0.51 \\
\hline Triglycerides, mg/dL & & $57.0(27.2)$ & $70.0(29.0)$ & $123.5(72.7)^{b, c}$ & $<0.0001$ \\
\hline LDL-C, mg/dL & & $98.0(30.5)$ & $100.0(34.0)$ & $101.0(28.5)$ & 0.57 \\
\hline Total cholesterol, mg/dL & & $181.0(48.7)$ & $169.0(42.0)$ & $173.0(34.5)$ & 0.13 \\
\hline ApoA-I, mg/dL & & $176.0(61.2)$ & $147.0(53.0)$ & $111.0(57.2)^{b, c}$ & $<0.0001$ \\
\hline ApoB, mg/dL & & $73.7(24.3)$ & $81.3(26.1)$ & $81.7(22.3)^{b}$ & 0.04 \\
\hline HDL-C, mg/dL & & $72.5(39.0)$ & $49.0(52.0)^{\mathrm{a}}$ & $32.5(15.0)^{\mathrm{b}, \mathrm{c}}$ & $<0.0001$ \\
\hline cIMT, mm & & $0.55(0.2)$ & $0.58(0.2)$ & $0.67(0.5)$ & 0.05 \\
\hline
\end{tabular}


631 All continuous variables are expressed as medians and interquartile ranges, and categorical

632 variables as percentages. Comparisons between groups were analyzed with Jonckheere-

633 Terpstra's for ordered alternatives with pairwise comparisons, or Chi-Square test for the

634 categorical variables. To convert the values for glucose to millimoles per liter, divide by 18 .

635 To convert the values for insulin to picomoles per liter, multiply by 6.945 . To convert the

636 values for cholesterol to millimoles per liter, multiply by 0.02586 . To convert the values for

637 triglycerides to millimoles per liter, multiply by $0.01129 .{ }^{\mathrm{a}} \mathrm{BMI} 22-24.9$ vs BMI $<22$; ${ }^{\mathrm{b}} \mathrm{BMI}$

$638>25$ vs $22-24.9 ;{ }^{\mathrm{c}} \mathrm{BMI}>25$ vs $\mathrm{BMI}<22$. Significant $\mathrm{p}$-value $<0.05$. 
medRxiv preprint doi: https://doi.org/10.1101/19002899; this version posted July 25, 2019. The copyright holder for this preprint (which was not certified by peer review) is the author/funder, who has granted medRxiv a license to display the preprint in perpetuity. It is made available under a CC-BY-NC-ND 4.0 International license .

Table 3. HDL characterization

BMI categories (kg/m2)

\begin{tabular}{|c|c|c|c|c|}
\hline & $<22$ & 22-24.99 & $25-30$ & p-value \\
\hline Sample size & 34 & 47 & 20 & \\
\hline Total mass, mg/dL & $198.8(91)$ & $182.3(98)$ & $155(99)^{\mathrm{c}}$ & 0.024 \\
\hline Triglycerides, mg/dL & $9.8(6.0)$ & $7.8(4.0)$ & $8.3(6)$ & 0.047 \\
\hline Free cholesterol, mg/dL & $8.0(6.0)$ & $6.3(4.0)^{\mathrm{a}}$ & $5.3(3.0)^{\mathrm{c}}$ & 0.001 \\
\hline Cholesteryl ester, mg/dL & $60.1(35)$ & $52.9(46)$ & $39.7(26)^{\mathrm{c}}$ & 0.004 \\
\hline Phospholipids, mg/dL & $35.1(19)$ & $29.2(14)^{\mathrm{a}}$ & $24.7(13)^{\mathrm{c}}$ & $<0.0001$ \\
\hline ApoA-I, mg/dL & $86.1(40)$ & $86.1(48)$ & $76.9(39)$ & 0.578 \\
\hline Total proteins, mg/dL & $135.5(71.5)$ & $143.6(74)$ & $\begin{array}{l}147.0 \\
(54.0)\end{array}$ & 0.777 \\
\hline HDL size, $\mathbf{n m}$ & $7.9(0.9)$ & $7.8(0.9)$ & $7.6(0.8)^{\mathrm{b}, \mathrm{c}}$ & $<0.0001$ \\
\hline Zeta potential, mV & $-7.7(5)$ & $-6.4(4)$ & $-7.8(9)$ & 0.297 \\
\hline CETP, \% & $10.1(6.4)$ & $10.6(7.3)$ & $10.7(6.3)$ & 0.612 \\
\hline PLTP, $\mu \mathrm{mol} \mathrm{PC/mL/h}$ & $5.7(2.9)$ & $6.0(3.2)$ & $5.4(3.5)$ & 0.338 \\
\hline LCAT, nmol CE/mL/h & $17.4(15)$ & $16.6(12)$ & $16.9(19)$ & 0.454 \\
\hline LPL, $\mu \mathrm{mol}$ FFA/mL/h & $4.0(3.4)$ & $3.7(3.7)$ & $3.2(2.9)$ & 0.157 \\
\hline HL, $\mu \mathrm{mol} \mathrm{FFA/mL/h}$ & $4.9(4.0)$ & $5.8(4.4)$ & $5.8(4.5)$ & 0.440 \\
\hline $\begin{array}{l}\text { PON/HDL-C, } \\
(\mathrm{mmol} / \mathrm{min}) /(\mathrm{mg} / \mathrm{dL})\end{array}$ & $0.40(0.5)$ & $0.50(0.7)^{\mathrm{a}}$ & $0.54(0.7)^{\mathrm{c}}$ & $<0.001$ \\
\hline
\end{tabular}


658 All continuous variables are expressed as medians and interquartile ranges. To convert values

659 for cholesterol to millimoles per liter, multiply by 0.02586 . To convert values for triglycerides

660 to millimoles per liter, multiply by $0.01129 .{ }^{\mathrm{a}} \mathrm{BMI} 22-24.9$ vs $\mathrm{BMI}<22$; ${ }^{\mathrm{b}} \mathrm{BMI}>25$ vs $22-$

$66124.9 ;{ }^{\mathrm{c}} \mathrm{BMI}>25$ vs $\mathrm{BMI}<22$. Significant $\mathrm{p}$-value $<0.05$.

662

663

664

665

666

667

668

669

670

671

672

673

674

675

676

677

678

679

680

681

682

683

684

685 
medRxiv preprint doi: https://doi.org/10.1101/19002899; this version posted July 25,2019 . The copyright holder for this preprint (which was not certified by peer review) is the author/funder, who has granted medRxiv a license to display the preprint in perpetuity.

It is made available under a CC-BY-NC-ND 4.0 International license .

686 Table 4. Linear regression analyses between HDL functions and cIMT

\begin{tabular}{|c|c|c|c|c|c|}
\hline $\begin{array}{l}\text { Independent } \\
\text { variable }\end{array}$ & Unstandardized $\beta$ & Standardized $\beta$ & $\begin{array}{l}\text { Lower } \\
\text { CI } 95 \%\end{array}$ & $\begin{array}{l}\text { Upper CI } \\
95 \%\end{array}$ & $p$-value \\
\hline $\begin{array}{l}\text { Antioxidant activity } \\
\text { Unadjusted } \\
\text { Adjusted }^{\mathrm{a}}\end{array}$ & $\begin{array}{l}-0.001 \\
-0.002\end{array}$ & $\begin{array}{l}-0.153 \\
-0.196\end{array}$ & $\begin{array}{l}-0.003 \\
-0.003\end{array}$ & $\begin{array}{l}0.000 \\
0.000\end{array}$ & $\begin{array}{l}0.128 \\
0.038\end{array}$ \\
\hline $\begin{array}{l}\text { CEC } \\
\text { Unadjusted }_{\text {Adjusted }^{\mathrm{a}}}\end{array}$ & $\begin{array}{l}-0.016 \\
-0.012\end{array}$ & $\begin{array}{l}-0.260 \\
-0.188\end{array}$ & $\begin{array}{l}-0.028 \\
-0.023\end{array}$ & $\begin{array}{l}-0.004 \\
0.000\end{array}$ & $\begin{array}{l}0.009 \\
0.047\end{array}$ \\
\hline $\begin{array}{l}\text { PON/HDL-C } \\
\text { Unadjusted }^{\text {Adjusted }}\end{array}$ & $\begin{array}{l}-0.010 \\
-0.045\end{array}$ & $\begin{array}{l}-0.063 \\
-0.061\end{array}$ & $\begin{array}{l}-0.079 \\
-0.071\end{array}$ & $\begin{array}{l}0.024 \\
0.019\end{array}$ & $\begin{array}{l}0.301 \\
0.254\end{array}$ \\
\hline $\begin{array}{l}\text { Anti-inflammatory } \\
\text { activity } \\
\text { Unadjusted }^{\text {Adjusted }} \\
\text { Ad }^{\mathrm{a}}\end{array}$ & $\begin{array}{l}0.000 \\
0.000\end{array}$ & $\begin{array}{l}-0.043 \\
-0.004\end{array}$ & $\begin{array}{l}-0.003 \\
-0.002\end{array}$ & $\begin{array}{l}0.002 \\
0.002\end{array}$ & $\begin{array}{l}0.676 \\
0.963\end{array}$ \\
\hline $\begin{array}{l}\text { HDL-mediated } \\
\text { platelet inhibition } \\
\text { Unadjusted } \\
\text { Adjusted }^{\mathrm{a}}\end{array}$ & $\begin{array}{l}0.002 \\
0.002\end{array}$ & $\begin{array}{l}0.164 \\
0.177\end{array}$ & $\begin{array}{l}0.000 \\
0.000\end{array}$ & $\begin{array}{l}0.004 \\
0.004\end{array}$ & $\begin{array}{l}0.120 \\
0.068\end{array}$ \\
\hline
\end{tabular}

${ }^{b}$ Adjusted for age, sex, BMI, HDL-C and insulin. In order to compare effects across different HDL functions we provided the standardized coefficients. 
medRxiv preprint doi: https://doi.org/10.1101/19002899; this version posted July 25, 2019. The copyright holder for this preprint (which was not certified by peer review) is the author/funder, who has granted medRxiv a license to display the preprint in perpetuity. It is made available under a CC-BY-NC-ND 4.0 International license.

688

689

690 
A.

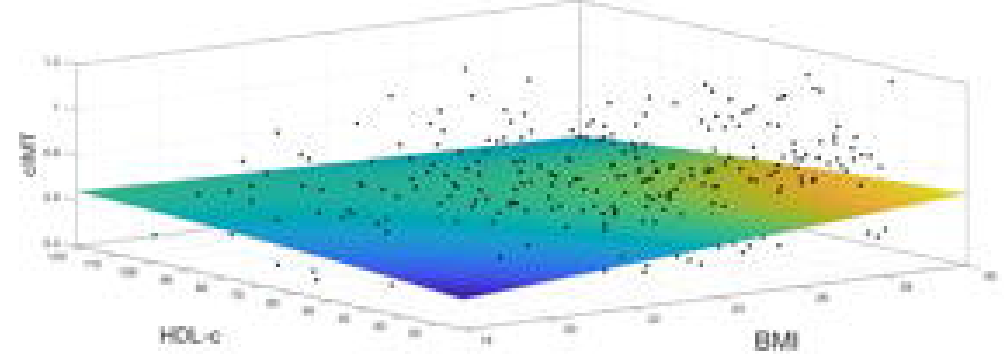

c.

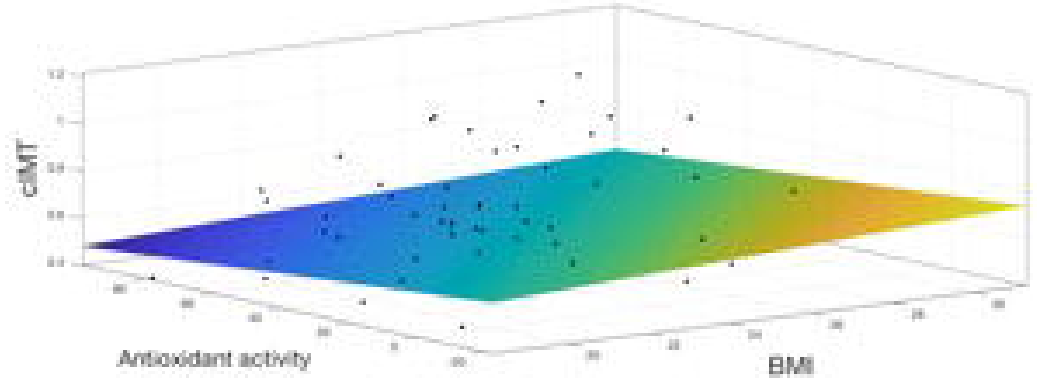

B.

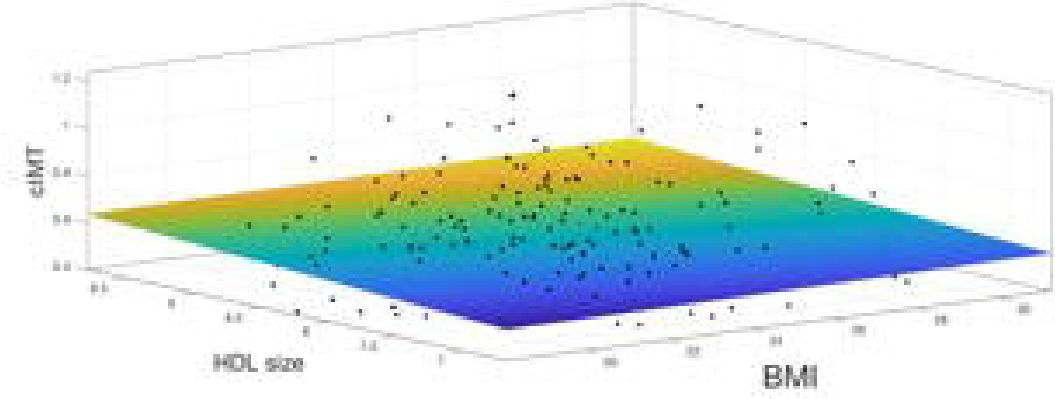

D.

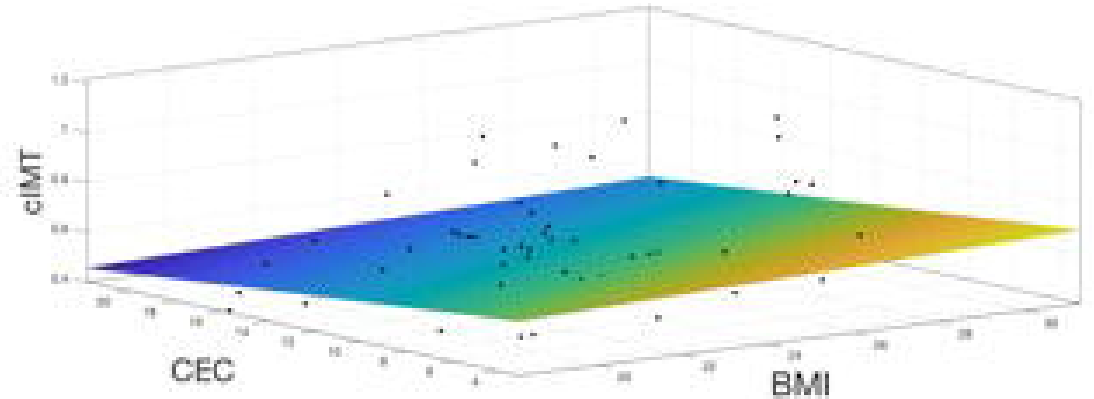


